\title{
Prevalence of Common Diseases among Internally Displaced Persons in a Selected Region of Central African Republic
}

\author{
Rasul MM1 , Chowdhury $\mathrm{AH}^{2}$, Romel $\mathrm{MSH}^{3}$, Sadat FMㄴ 4 , Hoque BS 5 \\ DOI: https:/ / doi.org/ 10.3329/ jafmc.v15i2.50831
}

\begin{abstract}
Introduction: Central African Republic (CAR) is one of the most war-affected countries in the world. The number of forcibly displaced people has grown significantly along with the emergence of many infectious and non-infectious diseases in this region. Very little information is available regarding the health of internally displaced persons (IDPs) of this country.
\end{abstract}

Objectives: To find out the prevalence of common diseases among IDPs of a selected region of CAR.

Materials and Methods: This descriptive cross-sectional study was conducted at a United Nations level-II hospital, run by Bangladesh medical contingent from November 2017 to October 2018. Patients of both sex irrespective of age who attended at least once to the medical outpatient department of the hospital included in the study.

Results: Out of 1561 respondents $57 \%$ were female with a female to male ratio1.3:1. Among the health problems identified, communicable diseases were $65.59 \%$ and non-communicable diseases $34.40 \%$. Malaria (21.19\%), diarrhoeal disease (17.86\%) respiratory tract infection (15.52\%) and HIVIAIDS (9.96\%) were the most common communicable diseases. Non-communicable diseases mainly affected the adult population where the prevalent diseases were hypertension $18.99 \%$ followed by diabetes mellitus $15.08 \%$, severe malnutrition $11.91 \%$ and mental and post-traumatic stress disorder (PTSD) 08.93\%.

Conclusion: Limited provisions on healthcare facilities imposes a huge health risk for the IDPs especially, easily preventable communicable diseases. An integrated effort from local and international bodies is required for the restoration of the basic health services to continued provision of medicines, medical appliance and provide community health education and thereby, improve the overall health status of this region.

Key-words: Internally displaced person, Central African Republic, UN Level II hospital.

\section{Introduction}

Disasters and conflicts often cause displacement of a large number of people due to the destruction of house, environment, religious and economic necessity ${ }^{1}$. The number of forcibly displaced people is growing rapidly. According to the UN Refugee Agency², this number has reached 51.2 million in 2013. Amongst these people two major groups are distinguished- refugees and internally displaced persons (IDPs). The former are people who, out of fear or persecution, have left their home country and are unable or unwilling to return to that country3. IDPs flee their homes for the same reasons as refugees but remain on the territory of their country of origin 4 . War remains the most important cause of refugee displacement. Central African Republic (CAR) is one of the most war-affected countries in the world. Internal displacement has significant effects on public health. These impacts may indirectly affect the war-torn area such as increased rates of malnutrition and infectious diseases. Several risk factors of communicable diseases work simultaneously during displacement. These factors include movement of a large number of populations and settlement in a temporary area, where overcrowding is usually associated with poverty, lack of safe water, poor sanitation and waste disposal, resulting in environmental and economic degradation. Moreover, these conditions are again compounded by the insufficient shelter, food supply and poor healthcare facilities ${ }^{5}$. Almost whole of Sub-Saharan Africa ${ }^{6,7}$ is affected by these factors resulting in an increased risk of easily preventable communicable diseases such as respiratory infections (ARI) (4\%), gastrointestinal infection (18\%-22\%) and skin disease (77\%-86\%). Furthermore, the nutritional problem has been reported ${ }^{8}$ among children under-five years which includes stunting (38.6\%), underweight (28.4\%) and wasting (7.2\%). Diarrhoeal diseases are one of the major health problems among IDPs and mainly resulting from inadequate and substandard sanitation facilities, lack of hygiene. The inadequacy of public health services also raises the vector-borne diseases (VBDs) like malaria and yellow fever ${ }^{9}$. Similarly, the disrupted routine immunization also increases the risk of epidemics of vaccine-preventable diseases (VPDs). Depending on the location, outbreaks of VPDs have been reported among IDPs includes measles (20\%-30\%) meningococcal meningitis (0.3\%) and cholera ${ }^{10}$, yellow fever and recently discovered Hepatitis $E^{11}$ have been reported in IDPs in Africa. Epidemics of many infectious diseases are very common in IDP camps which are due to inadequate water supply, sanitation facilities and overcrowding ${ }^{12}$. Over $70 \%$ of internally displaced populations are women and children. They are at a wide range of health risks and extremely vulnerable to mental and physical health issue ${ }^{13}$. Moreover, IDPs those affected particularly by conflict, are at an increased risk of psychological trauma. Most commonly found psychological conditions are post-traumatic stress disorders (PTSD) as a result of violence and depression to loss ${ }^{14}$. Other commonly found mental health problems are panic attacks and anxiety disorders. The distress following a post-conflict situation also contributes to abnormal behaviours like increased drinking and smoking. These sorts of behaviours contribute to an increased risk of non-communicable diseases such as hypertension, various respiratory disease conditions including cancer ${ }^{15}$. Despite significant efforts of international and local structures, many IDPs still lack sustainable shelter and sufficient health care.

1. Lt Col Md Maqsudur Rasul, MBBS, FCPS (Medicine), FCPS (Nephrology), Classified Specialist in Medicine and Nephrologist, BANMED-4, MINUSCA (Email: maqsud1049@gmail.com) 2. Col Amina Hasnat Chowdhury, MBBS, MPH, Contingent Commander, BANMED-4, MINUSCA 3. Maj Md Sazzad Hosen Romel, MBBS, Graded Specialist in Medicine, General Physician, BANMED-4, MINUSCA 4. Maj Fahad Mohammad Sadat, MBBS, MCPS, Graded Specialist in Pathology, BANMED-4, MINUSCA 5. Maj Bonny Sadar Hoque, MBBS, Medical Officer, BANMED-4, MINUSCA. 
Despite these huge numbers of IDPs and the negative effect of displacement on the health issue of these people, there is little information on this matter is found in the region. This study assesses the prevalence of the common disease among the IDPs of Central African Republic attending UN level-II hospital.

\section{Materials and Methods}

This study was conducted at BANMED-4, a UN level-II hospital in KagaBandoro district of Central African Republic from November 2017 to October 2018. This was an observational hospital-based cross-sectional study. The investigative methods used included questionnaire-based interview and diagnosis was made on clinical evaluation and laboratory methods. Purposive sampling was done among patients of both sex irrespective of age who presented at least once to the medical outpatient department of the hospital. The following data for each patient such as age, sex, height, weight were collected. Chronically ill patients diagnosed before their displacement were accepted based on the patient's documents. Categorization of diseases was done based on the International Statistical Classification of Disease (ICD-10) system. The study focused on the number of cases instead of the number of visits since a great number of patients visit OPD for checkups or follow-ups of previously diagnosed illnesses. A predesigned master data collection sheet was used for the recording of all data.

Though there is no universally accepted definition of common disease yet for the purpose of the study diseases which represent more than five percent of the total participants were considered as a common disease. Informed written consent was obtained from adult patients whereas, parents or guardians signed the informed consent on behalf of the patients below 18 years. The patients who did not give consent were excluded from the study. The ethical approval of the study was obtained from the ethical review committee of the hospital. BANMED-4 is working in collaboration with the United Nations Multidimensional Integrated Stabilization Mission in the Central African Republic (MINUSCA) as a UN level-II hospital. Data retrieved were analyzed using statistical package for social science (SPSS version 18 windows).

\section{Results}

The study revealed that the majority of the study population were in the age group between 25 to 35 years (29.72\%), followed by 35 to 45 years (26.77\%). The mean age of the patient was $27 \pm 16.50$ years and 53\% patients were male (Table-I). Out of 1561 cases, 1024 (65.59\%) were communicable disease and rest 537 (34.40\%) were noncommunicable disease. Among the non-communicable diseases, hypertension 102 (18.99\%) was most common, followed by diabetes mellitus 81(15.08\%), severe malnutrition 64(11.91\%) and mental and behavioural disorder of which sufferer of post-traumatic stress disorder (PTSD) 48(08.93\%) were more. The common communicable diseases in the study population among them malaria 217(21.19\%) are most the common, followed by diarrhoeal disease 183(17.87\%) and respiratory tract infection 159(15.52\%) (Table-II). Vaccinepreventable disease (VPD) like tuberculosis, viral hepatitis, and measles are also very common (Table-I). Out of 1561 cases, 890(57\%) were female and 671(43\%) were male, with female: male ratio1.3:1(Figure-1) Out of 1561 patients about half of them were suffering from five very common diseases like malaria (14\%), diarrhoeal disease (12\%), upper respiratory tract infection (10\%) and HIV (6\%). Hypertension (7\%) is also very common (Figure-1). Children were found to be the most vulnerable group for communicable disease. All the four most common communicable diseases have significantly affected the children under 15 years than the adult population (Figure-2). Adult people especially after the age of 35 years, IDPs start suffering from some common non-communicable disease like hypertension, diabetes mellitus and psychiatric disorder, except severe malnutrition which mostly affecting the children (15\%) (Figure-3). Most of the communicable disease like malaria, diarrhoeal disease are common in the rainy season (monsoon), however acute respiratory infection is common in winter (Figure-4).

Table-I: Distribution of age and sex of participant $(n=1561)$

\begin{tabular}{|c|c|c|c|}
\hline \multicolumn{2}{|r|}{ Traits } & Frequency & Percentage \\
\hline \multirow{8}{*}{ 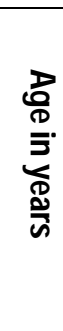 } & $<5$ & 56 & 3.58 \\
\hline & $05-15$ & 147 & 9.41 \\
\hline & $15-25$ & 302 & 19.34 \\
\hline & $25-35$ & 464 & 29.72 \\
\hline & $35-45$ & 418 & 26.77 \\
\hline & $45-55$ & 108 & 6.91 \\
\hline & $>55$ & 66 & 4.22 \\
\hline & \multicolumn{3}{|c|}{ Mean $( \pm S D) 27 \pm 16.50$} \\
\hline \multirow[t]{2}{*}{ Sex } & Male & 671 & 57 \\
\hline & Female & 890 & 43 \\
\hline
\end{tabular}

Table-II: Distribution of participants by diseases ( $n=1561$ )

\begin{tabular}{|c|c|c|c|c|}
\hline \multicolumn{2}{|c|}{ Types of Diseases } & ICD code & Frequency & Percentage \\
\hline \multirow{11}{*}{ 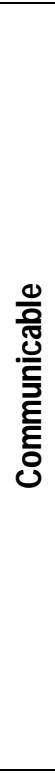 } & $\begin{array}{l}\text { Intestinal infectious } \\
\text { disease (Diarrheal } \\
\text { disease) }{ }^{1}\end{array}$ & A00-A09 & 183 & 17.87 \\
\hline & Tuberculosis & A15-A16 & 63 & 6.15 \\
\hline & $\begin{array}{l}\text { Viral infection of } \\
\text { skin² }\end{array}$ & B00-B05 & 61 & 5.95 \\
\hline & Viral hepatitis & B15- B17 & 52 & 5.02 \\
\hline & HIV IAIDS & B20-B24 & 102 & 9.96 \\
\hline & Malaria & B50-B51 & 217 & 21.19 \\
\hline & Helminthiasis 3 & B65-B77 & 59 & 5.76 \\
\hline & $\begin{array}{l}\text { Other infestation of } \\
\text { skin (Scabies, } \\
\text { Myasis) }\end{array}$ & B86-B87 & 74 & 7.22 \\
\hline & $\begin{array}{l}\text { Acute Respiratory } \\
\text { Infection }\end{array}$ & J00-J06 & 159 & 15.52 \\
\hline & $\begin{array}{l}\text { Urinary tract } \\
\text { infection }\end{array}$ & N30-39 & 54 & 5.27 \\
\hline & \multicolumn{2}{|l|}{ Total } & 1024 & $65.59 \%$ \\
\hline \multirow{11}{*}{ 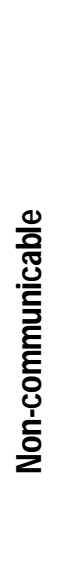 } & Diabetes mellitus & E11 & 81 & 15.08 \\
\hline & Severe Malnutrition & E45 & 64 & 11.91 \\
\hline & Depressive disorde & F33 & 27 & 05.02 \\
\hline & PTSD & F43 & 48 & 08.93 \\
\hline & Peptic ulcer disease & K27 & 43 & 08.00 \\
\hline & $\begin{array}{l}\text { Dorsalgia ( back } \\
\text { pain) }\end{array}$ & M54 & 59 & 10.98 \\
\hline & $\begin{array}{l}\text { Essential } \\
\text { hypertension }\end{array}$ & 110 & 102 & 18.99 \\
\hline & $\begin{array}{l}\text { Ischemic heart } \\
\text { disease }\end{array}$ & 125 & 43 & 08.00 \\
\hline & Asthma & $\mathrm{J} 45$ & 32 & 05.95 \\
\hline & Headache & R51 & 38 & 07.07 \\
\hline & \multicolumn{2}{|l|}{ Total } & 537 & $34.40 \%$ \\
\hline
\end{tabular}

Note: 1. Diarrhoeal disease includes cholera, typhoid \& paratyphoid fever, shigelosis, amoebiasis

2. Measles, chicken pox 3. Schistosomiasis, Ascariasis 


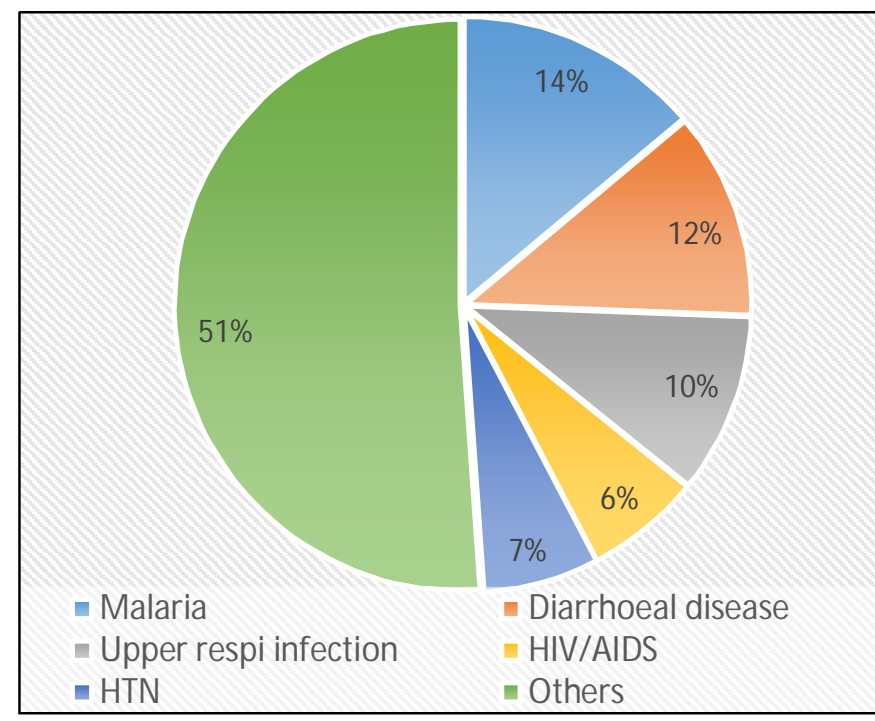

Figure-1: Common disease among the study population $(n=1561)$

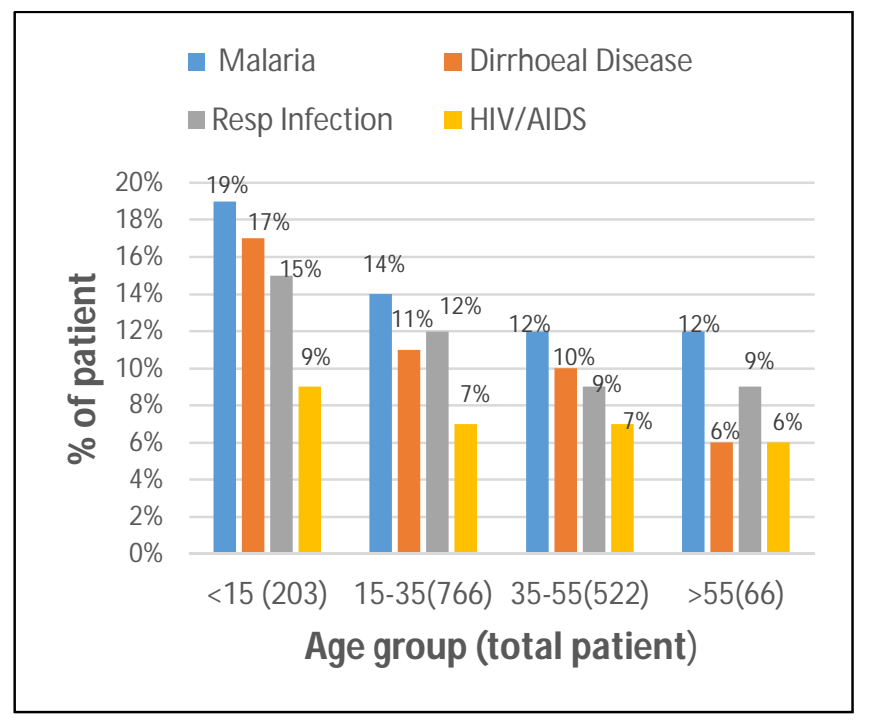

Figure-2: Distribution of common communicable diseases as per age group $(n=1024)$

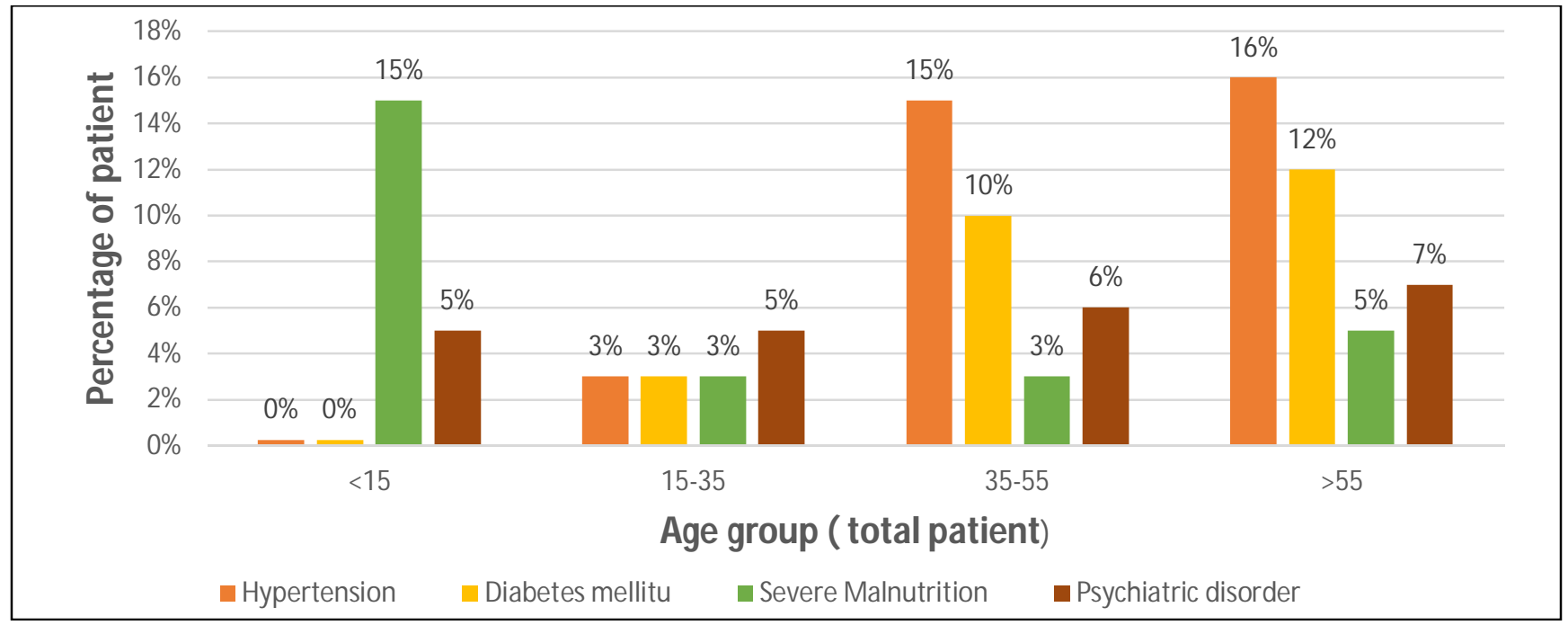

Figure-3: Distribution of non-communicable disease as per age group $(n=537)$

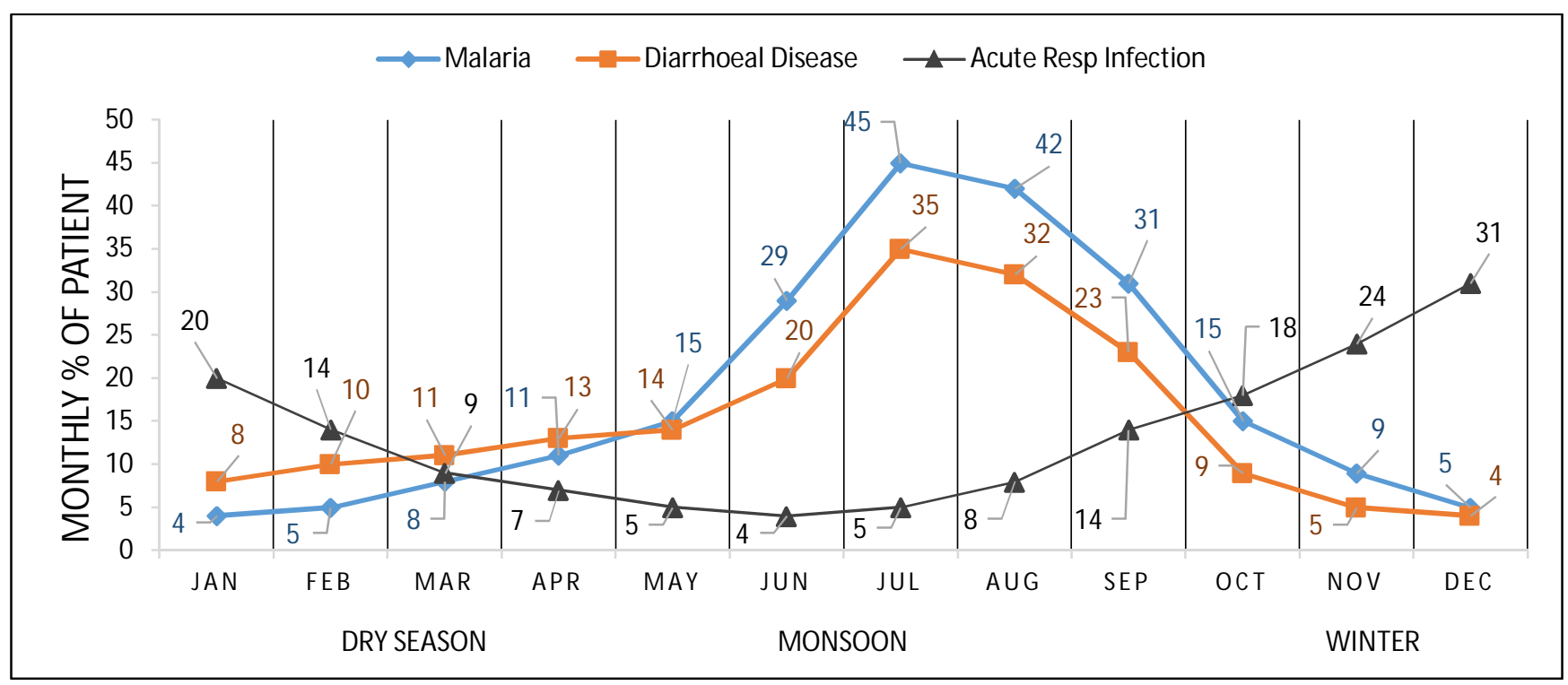

Figure-4: Seasonal distribution of common infectious disease 


\section{Discussion}

In this grave scenario of the huge numbers of displaced and distressed people in the Central African Republic and their greater risk to a various infectious and non-infectious diseases, it is necessary to gather information on the burden of various common diseases in these populations. In this study, it is found that among 1561 participant, the majorities are female, and the female-male ratio is 1.3:1. The main health problems identified were mostly communicable diseases (65.59\%) and rest are non-communicable (34.4\%) diseases. There are other health-related problems as well such as substance misuse and sexual abuse. From this study, the most prevalent communicable diseases among children and adults were malaria $(21.19 \%)$, diarrhoeal disease $(17.86 \%)$ respiratory tract infection (15.52\%) and HIVIAIDS (9.96\%). The high prevalence of these communicable diseases among the IDPs are also reported by Alan Garcia-Ramos in the Borgen Project ${ }^{16,17}$ which could be due to various environmental factors such as poor sanitation, waste disposal, inadequate supply drinking water and overcrowding ${ }^{18}$. IDPs are also susceptible to many VPDs such as tuberculosis, measles, viral hepatitis and meningitis as shown in table 4. However, research reports of many humanitarian agencies have also shown a high prevalence of such diseases among displaced populations. Similarly, occurrences of other VPDs of such as viral hepatitis 18 meningococcal meningitis have been reported among displaced Sub-Saharan African population. On the other hand, the burden of non-communicable diseases (34.40\%) is not as high as infectious disease. We found that hypertension was the most common one (18.99\%), followed by diabetes mellitus (15.08\%), malnutrition $(11.91 \%)$, diseases of the musculoskeletal system (10.98\%) and mental and behavioural disorder like depressive disorder and PTSD among the non-communicable disease study population. The World Health Organization report on the country profile of the Central African Republic showed a similar prevalence of non-communicable disease ${ }^{19}$. Alcohol consumption and smoking are one of the contributing factors confounded by the scarcity of medical facilities. Considering the age of the participants the prevalence of communicable diseases was much higher among children indicating that they are most vulnerable in IDP camps. Ahmed et al. in his surveillance study showed that the same high incidence of acute respiratory infection among children below 5 years in two IDPs camps in Kenya ${ }^{20}$. Due to poverty, complications of various infectious diseases along with poor access to health facilities malnutrition become a great burden in the camp. In this study was found that $15 \%$ of children were severely malnourished. Similarly, Gbakima et al in his study in Freetown found that 21.2\% of children in all the four IDPs camps were stunted21. Furthermore, a good number of adults have also been found underweight in this study. Similarly, in a study by Singh et al on the nutritional condition of man and woman aged 18 years and above in Kenya 22 found that $23 \%$ of them were underweight. Rests of the common, non-communicable disease are more prevalent after 35 years. One of the most common non-communicable diseases found among these displaced people in this study was mental health such as depression $(5,02 \%)$ and PTSD (08.93\%). Studies have shown that mental health effects following conflicts tend to be worse than those from natural disasters ${ }^{23}$.

The CAR is a sub-Saharan tropical country and climate is mostly divided into three seasons namely dry season or summer (January to April), rainy season or monsoon (May to October) and winter
(November to December). In this study, most of the prevalent communicable disease burden like malaria, diarrhoeal disease and respiratory tract infection increased in monsoon. During summer diarrhoeal disease, bacterial meningitis was also common. During winter, though temperature variation is not much, the acute respiratory infection was increased many folds during this time.

\section{Conclusion}

Results from this study indicate that various infectious diseases were prevalent among the IDPs; although chronic NCDs are also a major health issue. There are limited facilities on health matter in this region especially for easily preventable communicable disease. However, the study recommends implementation of previous advises from authoritative bodies especially WHO, UNHCR to re-establish the basic and emergency healthcare facilities, including hospital and community clinic, continued supply of medicines and health education for the improvement of this grave condition.

\section{References}

1. Global Overview 2014: People internally displaced by conflict and violence. IDMC 2014.

2. UNHCR. New UNHCR report says global forced displacement at 18-year high. Available: http://www.unhcr. [Accessed 12th of January 2015.

3. UNHCR 1951. United Nations Convention Relating to the Status of Refugees.

4. Siriwardhana C, Ali SS, Roberts B et al. A systematic review of resilience and mental health outcomes of conflict-driven adult forced migrants. Conflict Health 2014; 8:13.

5. The Sphere Handbook. Minimum standards in health action. In: The Sphere Project: Humanitarian Charter and Minimum Standards in Disaster Response 2011:287-354.

6. Kim G, Torbay R, Lawry L. Basic health, women's health and mental health among internally displaced persons in Nyala Province, South Darfur, Sudan. Am J Public Health 2007; 97:353-61.

7. Getanda EM, Papadopoulos C, Evans H. The mental health, quality of life and life satisfaction of internally displaced persons living in Nakuru County, Kenya. BMC Public Health 2015; 15:755.

8. Turnip SS, Klungsøyr O, Hauff E. The mental health of populations directly and indirectly exposed to violent conflict inIndonesia. Conflict Health 2010; 4:14.

9. Connolly MA, Gayer M, Ryan MJ et al. Communicable diseases in complex emergencies: Impact and challenges. Lancet 2004; 364:1974-83.

10. Shultz A, Omollo JO, Burke $\mathrm{H}$ et al. Cholera outbreak in Kenyan refugee camp: Risk factors for illness and importance of sanitation. Am J Trop Med Hyg 2009; 80:640-5.

11. World Health Organization. Health Action in Crises (WHO/HAC). Highlights. Geneva: World Health Organization; 2008.

12. Siriwardhana $\mathrm{C}$, Wickramage $\mathrm{K}$. Conflict, forced displacement and health in Sri Lanka: A review of the research landscape. Conflict Health 2014; 8:22.

13. Norwegian Refugee Council. IDMC. Global Report on Internal displacement (GRID) 2016; 8:13. 
14. Getanda EM, Papadopoulos C, Evans H. The mental health, quality of life and life satisfaction of internally displaced persons living in Nakuru County, Kenya. BMC Public Health2015; 15:755.

15. Roberts B, Patel P, McKee M. Non-communicable diseases and post conflict countries. Bull World Health Organ 2012; 90:2, 2A.

16. http://borgenproject.org/ 4common disease in Central African Republic.

17. Owoaje ET, Uchendu OC, Ajayi TO et al. A Review of the Health Problems of the Internally Displaced Persons in Africa. Niger Postgrad Med J 2016; 23(4):161-71.

18. Lam E, McCarthy A and Brennan M. Vaccine-preventable diseases in humanitarian emergencies among refugee and internally displaced populations. Hum Vaccin Immunother 2015; 11:2627-36.
19. World Health Organization - Non-communicable Diseases (NCD) Country Profiles, 2014.

20. Ahmed JA, Katz MA, Auko E et al. Epidemiology of respiratory viral infections in two long term refugee camps in Kenya, 2007-2010. BMC Infect Dis 2012; 12:7.

21. Gbakima A, Richard K, Namisa K et al. Sierra Leone journal of biomedical research nutritional status of children in displacement camps in Sierra Leone. Sierra Leone J Biomed Res 2012; 4:22-31.

22. Singh KP, Bhoopathy SV, Worth $\mathrm{H}$ et al. Nutrition among men and household food security in an internally displaced person's camp in Kenya. Public Health Nutr2016; 19:723-31.

23. Sheikh TL, Mohammed A, Agunbiade $\mathrm{S}$ et al. Psycho-trauma, psychosocial adjustment and symptomatic post-traumatic stress disorder among internally displaced persons in Kaduna, Northwestern Nigeria. Front Psychiatry 2014; 5:127. 